\title{
A modified single-armed microsurgical vasoepididymostomy for epididymal obstructive azoospermia: intraoperative choice and postoperative consideration
}

Nachuan Liu ${ }^{1+}$, Peng $\mathrm{Li}^{1+}$, Erlei Zhi ${ }^{1}$, Chencheng Yao ${ }^{1}$, Chao Yang ${ }^{1}$, Liangyu Zhao ${ }^{1}$, Ruhui Tian ${ }^{1}$, Huixing Chen ${ }^{1}$, Yuhua Huang ${ }^{1}$, Yuexin $\mathrm{Yu}^{2}$ and Zheng $\mathrm{Li}^{1^{*}}$

\begin{abstract}
Background: To evaluate the clinical outcomes and the duration required for the sperm to return to the ejaculate after a modified single-armed 2-suture longitudinal intussusception vasoepididymostomy (SA-LIVE).

Methods: From March 2015 to December 2018, 134 patients with epididymal obstruction azoospermia underwent the modified single-armed vasoepididymostomy at Shanghai General Hospital. The outcomes and clinical findings were documented and evaluated. The mean follow-up period was 17 (range: 3-36) months.

Results: Patency was assessed by the return of sperm in the ejaculate. The overall patency rate was $55.2 \%$, and the patency rates were 58.9, 40.7, 36.4, and 58.9\% for bilateral surgery, unilateral surgery, proximal anastomosis, and distal anastomosis, respectively. The average time to achieve patency was $4.11 \pm 2.74$ months. In the first 6 months, $87.8 \%(65 / 74)$ patency patients reported sperm in the ejaculate. The overall pregnancy rate was $40.9 \%(29 / 66)$ at the follow-up of 3-36 months, and the natural pregnancy rate was 30.3\% (20/66). The natural pregnancy rate was 32.1\% post-bilateral surgery and $33.3 \%$ for the site of distal anastomosis; surprisingly, it was $0 \%$ for the site of proximal anastomosis.
\end{abstract}

Conclusion: Modified SA-LIVE is safe and may achieve favorable patency and pregnancy rates. When double-armed sutures are not accessible, single-armed may be preferable. The expected patency time was within 1 year. Moreover, because of the low natural pregnancy rate for proximal anastomosis, sperm banking is preferred to SALIVE.

Keywords: Obstructive azoospermia, Male infertility, Vasoepididymostomy, Patency, Pregnancy

\footnotetext{
* Correspondence: lizhengboshi@sjtu.edu.cn

${ }^{\dagger}$ Nachuan Liu and Peng Li contributed to the work equally and should be regarded as co-first authors.

'Department of Andrology, the Center for Men's Health, Urologic Medical Center, Shanghai Key Laboratory of Reproductive Medicine, Shanghai General Hospital, Shanghai Jiao Tong University, Shanghai 200080, China Full list of author information is available at the end of the article
}

(C) The Author(s). 2020 Open Access This article is licensed under a Creative Commons Attribution 4.0 International License, which permits use, sharing, adaptation, distribution and reproduction in any medium or format, as long as you give appropriate credit to the original author(s) and the source, provide a link to the Creative Commons licence, and indicate if changes were made. The images or other third party material in this article are included in the article's Creative Commons licence, unless indicated otherwise in a credit line to the material. If material is not included in the article's Creative Commons licence and your intended use is not permitted by statutory regulation or exceeds the permitted use, you will need to obtain permission directly from the copyright holder. To view a copy of this licence, visit http://creativecommons.org/licenses/by/4.0/. The Creative Commons Public Domain Dedication waiver (http://creativecommons.org/publicdomain/zero/1.0/) applies to the data made available in this article, unless otherwise stated in a credit line to the data. 


\section{Background}

Azoospermia affects $1 \%$ of the general population and $10-15 \%$ of infertile men [1]. Obstructive azoospermia, primarily caused by epididymal obstruction, is diagnosed in approximately $40 \%$ of azoospermic men [2, 3]. Microsurgical vasoepididymostomy (MVE) has been established as a more cost-effective alternative for men with obstructive azoospermia than direct assisted reproductive techniques (ART) [4]. MVE necessitates superior surgical skills and meticulous surgical technique. Cornell et al. first reported that the single-armed 2-suture longitudinal intussusception vasoepididymostomy (SA-LIVE) was similar to that of the double-armed procedure in an animal study [5]. Zhao et al. reported the modified single-armed VE technique with favorable patency in a human study trial [6]. Previous studies have shown that a high patency rate may be related to factors, such as epididymal fullness, unilateral or bilateral procedure, and site of anastomosis [7]. However, only a few studies have assessed the clinical outcomes and the time of sperm returning to the ejaculate after SA-LIVE. Thus, in the present study, we aimed to evaluate the fertility outcomes of MVE in 134 males with epididymal obstruction and identify the putative predictors for natural pregnancy. Also, novel intraoperative procedures and decision-making post-operation were explored.

\section{Methods}

\section{Subjects and laboratory examination}

From March 2015 to December 2018, 158 patients who suffered from epididymal obstruction azoospermia (EOA) underwent VE surgery in our center (four patients were misdiagnosed with NOA previously, and one patient had VE in another hospital 2 years ago). However, during the follow-up, we collected the data from the semen analysis of 134 patients from our center or telephonic follow-up. In this cohort, 80/134 (55.9\%) of the patients had a previous history of urological or genital infection before the study, and the etiology of the other 54 cases remained unknown. None of the patients underwent a vasectomy in this study.

All patients underwent semen analysis at least three times before surgery. No sperm was detected in a centrifugal $(1500 \times g)$ semen assay, and ejaculate fructose tests were positive. The sex hormone levels, such as folliclestimulating hormone (FSH) and testosterone (T), in the serum, were within normal limits. Scrotal ultrasonography showed dilation of the epididymal tube if present. These were objective measurements for obstructive azoospermia [3].

\section{Diagnostic clinical condition and criteria}

The diagnostic criteria for inclusion in the study were as described previously [8]: obstruction was suspected when the infertile male had normal ejaculate volume with azoospermia; the physical examination showed non-atrophic testes with normal vas deferens bilaterally, slightly swollen epididymis, and bilateral or unilateral hard epididymal nodules; normal serum total T and FSH levels; the ultrasonography showed the dilation of epididymal tube without dilation of the ejaculatory duct or seminal vesicle. The patients with chromosomal or sex chromosomal abnormalities, history of vasectomy, or whose female partners were reported to be infertile, were excluded from the current study.

\section{Surgical procedure \\ General preparation}

All patients underwent scrotal exploration under general anesthesia. Surgeries were performed by two experienced surgeons. Testis was exposed and biopsy was performed as follows: a touch-prep is made by blotting the cut surface of the testis several times on a glass slide and adding a drop of human tubal fluid and a coverslip. The samples were examined under high power using a light microscope with phase contrast that revealed the presence of sperm with tails and facilitated the assessment of motility. Subsequently, normal spermatogenesis was confirmed $[9,10]$. All patients provided written informed consent before the study.

\section{Microsurgical preparation}

A 24-gauge angiocatheter sheath was used to cannulate the lumen of the vas deferens, and Trypan blue was injected to judge the patency of the seminal vesicle side. A sufficient length was freed to allow the most proximal convoluted portion of the vas to be later brought to the lateral aspect against the epididymis without tension.

\section{Microsurgical SA-LIVE approach}

A Carl Zeiss S88 operating microscope (Carl Zeiss Shanghai Co., Ltd., Shanghai, China) was used to perform the microsurgical procedure at a magnification of 8-15X. A dilative epididymal tubule was selected and dissected under microscopic guidance. Subsequently, anastomosis was performed using the modified SA-LIVE technique (Fig. 1). Two single-armed 10-0 nylon sutures (Ethicon W2790, length $200 \mathrm{~mm}$, circle 3/8) were prepared for the intussusception sutures. The first suture was placed in an outside-in fashion through the mucosal layer of the vas deferens at point a1. Then, the needle was used to pierce the lateral aspect of the epididymal tubule and placed longitudinally. The second 10-0 single-armed proline suture was placed identically through point b1 on the vas deferens, parallel to the first suture on the contralateral side of the epididymal tubule. The two needles were used to parallelly pierce the epididymal tubule laterally within and longitudinally on the 


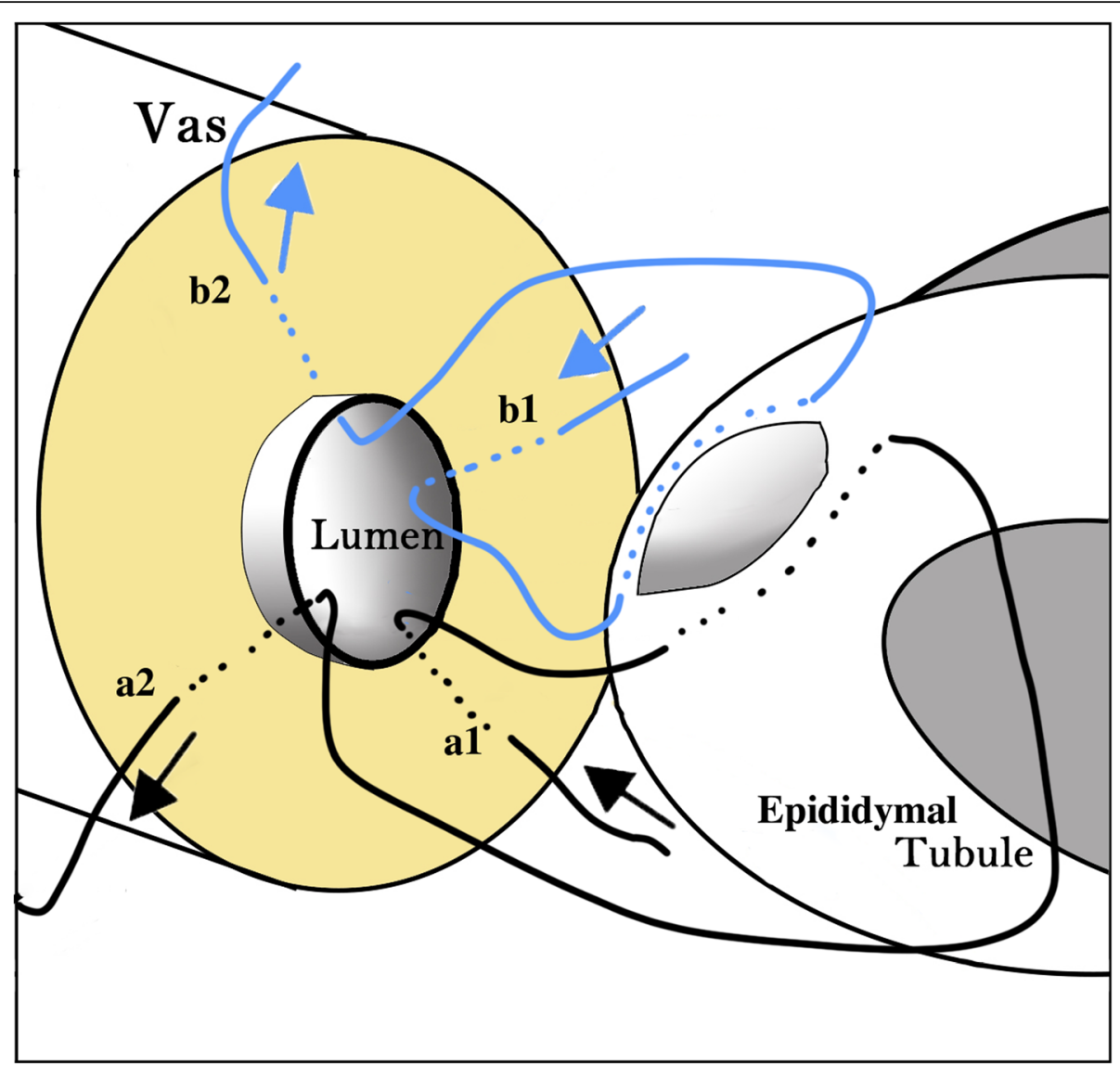

Fig. 1 Placement of sutures in modified SA-LIVE. The needles were sequentially placed outside-in (a1 and b1) through the mucosal layer of the vas deferens, parallelly through the epididymal tubule, then placed inside-out (a2 and b2) through the mucosal layer of the vas deferens

outside of the tubule. The epididymal tubule was opened longitudinally between the two sutures using a micro knife, and the exuded epididymal fluid was examined for sperm [10]. If the sperm or sperm fragments were present, the needles were pulled through the wall of the epididymis and placed in an inside-out manner through the full layer of the vas at positions a 2 and b2. Finally, all the sutures were tied together ( $a 1$ to $a 2$ and b1 to b2), and the epididymal tubule was gently intussuscepted into the lumen of the vas deferens. Then, the epididymal tunic was secured to the vassal muscle and adventitia with an 8-0 nylon suture. The epididymal and testicular sperms were cryopreserved during VE as a backup of the procedure.

\section{Postoperative management}

Most of the patients were discharged home on the 1st day after the surgery. They were advised to refrain from any heavy lifting and sports activity for 8 weeks postsurgery, and asexual abstinence was instructed for 4 weeks. Semen analyses were initiated at 4 weeks after surgery, and every month after that, until pregnancy was achieved. Patency was defined as the sperm concentration $>1$ million $/ \mathrm{ml}$ in at least one postoperative ejaculate sample. Pregnancy was defined as the establishment of a fetal heartbeat. The follow-up information was obtained by clinic visits and telephonic contacts. Patients without a postoperative semen analysis or patients lost to follow-up were excluded from the report, and the follow-up time was at least 3 months.

\section{Statistical analysis}

The patency and pregnancy rates of each group (unilateral and bilateral MVE group and the proximal and distal anastomosis group) were calculated. The chi-square test was used for all analyses. $P<0.05$ indicated statistical significance.

\section{Results}

From March 2015 to December 2018, a total of 158 patients diagnosed with an epididymal obstruction underwent modified SA-LIVE in our center; among these, 134 were followed up in a prospective study. Reportedly, 80 patients had a history of epididymitis or orchitis; full epididymis could be palpated easily with inflated nodes. The diagnostic ultrasonography findings also proved the 
existence of inflammation in the scrotum based on the thin net-like ectasia of the epididymal tube with the inner diameter up to $0.4 \mathrm{~mm}$ [11]. The mean age of the included patients was $32.1 \pm 6.7$ (range: $23-50$ ) years, and the mean follow-up was for $17 \pm 3.3$ (range: 3-36) months. The mean FSH and $\mathrm{T}$ levels were $4.3 \pm 2.4$ $\mathrm{mIU} / \mathrm{mL}$ and $5.0 \pm 2.9 \mathrm{ng} / \mathrm{mL}$, respectively. The mean testicular size was $15.4 \pm 3.3 \mathrm{~cm}^{3}$ as measured by ultrasonography (Table 1).

A total of 132 patients were subjected to sperm banking during the operation in the case of future intracytoplasmic sperm injection (ICSI). Sperm was present in the ejaculate of $74 / 134$ (55.2\%) patients after the surgery, and the average time to achieve patency was $4.11 \pm 2.74$ months. In the first 6 months post-treatment, 87.8\% (65/ 74) patients were reported to have sperm in their ejaculate. Only $12.2 \%$ (9/74) patients claimed to achieve patency in the following 6 months (Fig. 2). The variables related to patency for follow-up are listed in Table 2 . The patency rate was $58.9,40.7,36.4$, and $58.9 \%$ for bilateral surgery, unilateral surgery, proximal anastomosis, and distal anastomosis, respectively. In this cohort, $30.3 \%(20 / 66)$ patients were reported to have spontaneous pregnancy after VE. The variables related to natural pregnancy are listed in Table 3. The natural pregnancy rate was $30.5 \%$ for bilateral surgery, $20 \%$ for unilateral surgery, and $33.3 \%$ for the site of distal anastomosis, but $0 \%$ for the proximal anastomosis. Furthermore, nine couples got pregnant by ICSI (seven used frozen sperm collected during the operation, and two used fresh sperm from the ejaculate). The total and natural pregnancy rate was $43.9 \%(29 / 66)$ and $30.3 \%(20 / 66)$, respectively, at the follow-up of 3-36 months. The mean time to achieve natural pregnancy was $11.05 \pm$ 5.75 (range: 3-24) Months.

Table 1 Preoperative characteristics and intraoperative choices in all 134 patients

\begin{tabular}{ll}
\hline Items & Value \\
\hline Age (year), mean & \\
$\quad$ Patients & $32.1 \pm 6.7$ (ranged 23-50) \\
Female partners & $27.2 \pm 3.7$ (ranged 20-43) \\
Serum FSH (mIU/mL), mean & $4.3 \pm 2.4$ \\
Serum total testosterone $(\mathrm{ng} / \mathrm{mL})$, mean & $5.0 \pm 2.9$ \\
Testicular size $\left(\mathrm{cm}^{3}\right)$, mean & $15.4 \pm 3.3$ \\
Surgery, $\mathrm{n}(\%)$ & \\
$\quad$ Bilateral & $107(79.9 \%)$ \\
$\quad$ Unilateral & $27(20.1 \%)$ \\
Anastomotic site, $\mathrm{n}(\%)$ & \\
$\quad$ Proximal & $22(16.4 \%)$ \\
Distal & $112(83.6 \%)$ \\
\hline
\end{tabular}

\section{Discussion}

Approximately $10-15 \%$ of infertile men suffer from azoospermia, while about $40 \%$ suffer from obstructive azoospermia (OA). This obstruction may be attributed to bilateral occlusion at any point in the reproductive ductal system, which comprises of the efferent duct, epididymis, vas deferens, and the ejaculatory ducts. Unlike the USA, EOA is rarely caused by vasectomy rather by infection in China [12, 13]. The microsurgical anastomosis, including microsurgical vasovasostomy (VV), cross vasovasostomy (CVV), and vasoepididymostomy (VE), is considered as the most successful measure for a reversal [14]. Herein, we discussed the modified singlearmed 2-suture longitudinal intussusception vasoepididymostomy. The data were similar to the previously reported patency rate of $52-92 \%$ and the pregnancy rate of $11-56 \%[15,16]$. In the present cohort, we evaluated the pre-, intra-, and postoperative variables of individual patients that might affect the outcomes of the modified SA-LIVE.

The VE with the double-armed suture is the standard golden management for the EOA, and LIVE simplifies the anastomosis and improves the outcomes [7, 17]. However, in China, these specialized double-armed sutures for male infertility microsurgery are challenging, while access to single-armed microsurgical sutures is easy [18]. Furthermore, the cost of a single-armed sutures was cheaper than that of the double-armed microsurgical sutures. Therefore, SA-LIVE should be designated as an effective alternative when doublearmed sutures are not available. When the needles are in the tubule, the two sutures in a lower position can avoid the crossing of the sutures [6]. The two knots of the suture are left outside during the procedure, which might decrease the possibility of fibrosis and anastomotic stricture. However, the single-armed suture is timeconsuming as compared to the double-armed suture, which was placed inside-out on the vas deferens to avoid back-walling the tubular lumen. Since the single-armed suture was used in this study, the needle passed through the inferior points of the vasal mucosal layer in an outside-in manner through the epididymal tubule, and finally through the superior points of the vasal mucosal layer in an inside-out fashion, which was double timeconsuming than the double-armed suture, thereby increasing the risks of surgery. Also, we had to dilate the vasal lumen sufficiently wide to pass the needle through the lumen with the aid of a microneedle holder to avoid back-walling during the suture placement. Supposedly, these procedures must be completed before the presence of the sperm in the epididymal fluid [19]. However, if no sperm was detected, the procedure was repeated 2-4 times, which would significantly increase the time required for the surgery and the fatigue of the surgeon. 


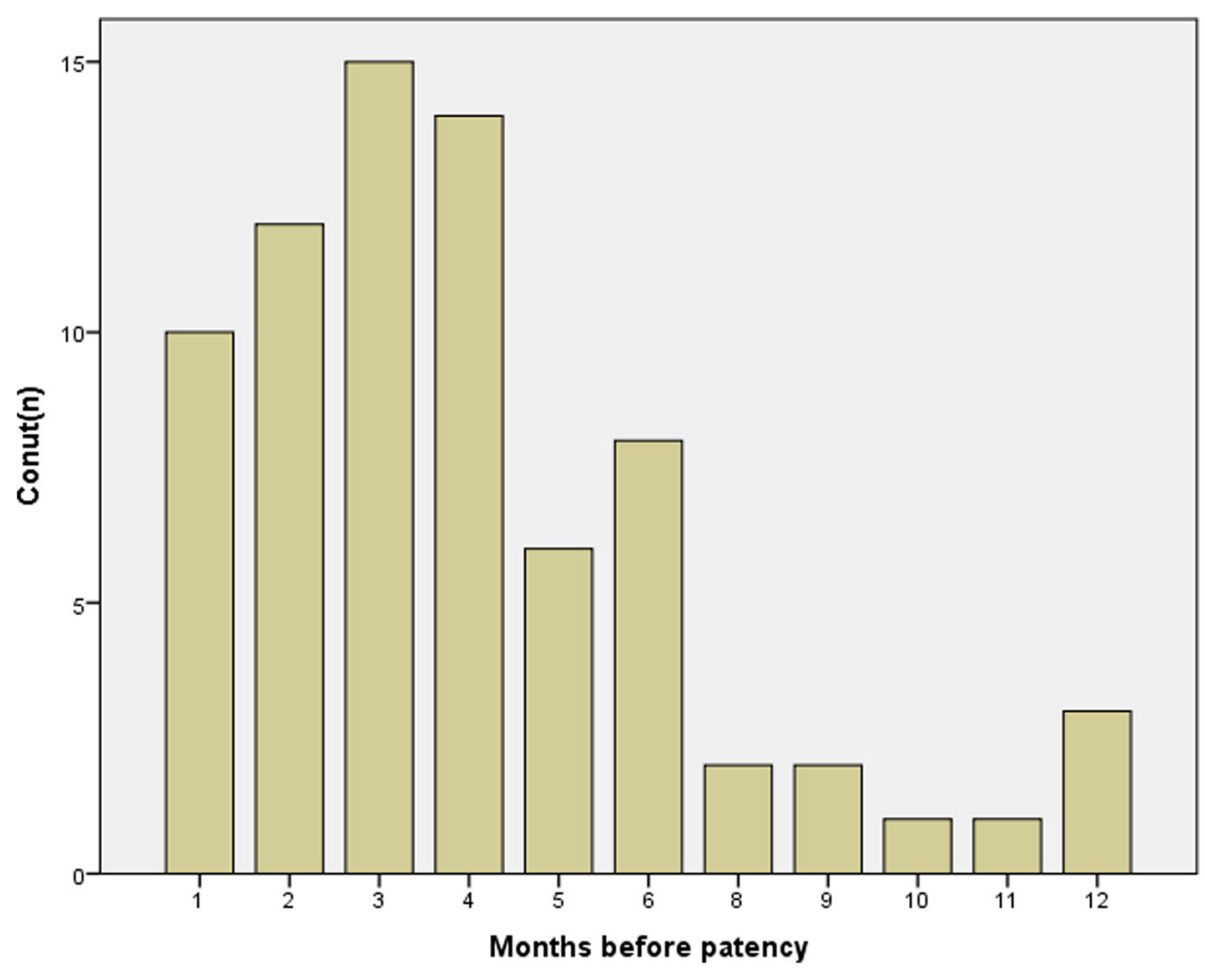

Fig. 2 Time of sperm returning to the ejaculate. The column height of the histogram represents the patients counts within various periods to achieve patency

In this cohort, the patency and the pregnancy rates were similar to those reported previously [12]. However, no statistically significant associations were found between the patency rate and various predictors, such as bilateral or unilateral anastomosis and anastomotic site $(P>0.05$; Tables 2 and 3$)$. Moreover, the natural pregnancy rate was $0 \%$ for the proximal anastomosis group, while it was $33.3 \%$ for the distal group, which prompted us to investigate whether patients can benefit from proximal anastomosis. Firstly, the luminal diameters of epididymal tubules in the caput were significantly smaller than those in the corpus and caudal, and hence, the modified SA-LIVE on the distal epididymis was more accessible than that on the proximal epididymis. Moreover, spermatozoa could become fully motile as well as recognize and fertilize an egg within the epididymis,

Table 2 The patency rate stratified by two variables for 134 patients

\begin{tabular}{llr}
\hline Variable & Patency $(\mathrm{n})$ & $P$ Value \\
\hline Surgery & & 0.090 \\
Bilateral & $63 / 107(58.9 \%)$ & \\
Unilateral & $11 / 27(40.7 \%)$ & \\
Anastomosis site & & \\
Proximal & $8 / 22(36.4 \%)$ & \\
Distal & $66 / 112(58.9 \%)$ & \\
\hline
\end{tabular}

which might improve the pregnancy rate. As the sample size was not sufficient for further investigation, the reason for the failure of the technique is yet to be determined.

Although there have been many clinical studies on VE, none proposed a specific follow-up time frame on SALIVE. The current study revealed that $87.8 \%$ of the patients achieved patency within 6 months postoperation, and none achieved patency since then, suggesting that SA-LIVE on patency can be followed up to 12 (average: $4.11 \pm 2.74$ ) months. The patency rate for the first 6 months was 48.5\% (65/134) and 11.4\% (9/69) for the next 6 months. Previous data on the mean time to achieve patency after vasovasostomy and vasoepididymostomy ranged from 1.7-4.3 and 2.8-6.6 months, respectively [12], which is in agreement with the current

Table 3 The natural pregnancy rate stratified by two variables for 134 patients

\begin{tabular}{llr}
\hline Variable & Natural pregnancy $(\mathrm{n})$ & $P$ Value \\
\hline Surgery & & 0.442 \\
$\quad$ Bilateral & $18 / 56(32.1 \%)$ & \\
Unilateral & $2 / 10(20.0 \%)$ & 0.090 \\
Anastomosis site & \\
$\quad$ Proximal & $0 / 6(0 \%)$ & \\
Distal & $20 / 60(33.3 \%)$ & \\
\hline
\end{tabular}


results. This finding could be valuable for the clinicians and researchers to predict the outcome of patients undergoing SA-LIVE as well as the precise time to transfer to ART.

Notably, four patients were diagnosed as nonobstructive azoospermia in other hospitals previously according to the negative results of the testis histopathology; however, we found motile sperm through the routine testicular biopsy. Thus, the scheduled operation of microdissection was transferred to $\mathrm{VE}$, and $3 / 4$ patients achieved patency afterward. This suggested that the testis biopsy during the operation is essential [20].

Also, one patient, who had undergone VE in another hospital previously was subjected to VE operation due to the previous failure. Consequently, sperm appeared in the ejaculate, and finally, this couple achieved a spontaneous pregnancy. Thus, we concluded that in addition to ICSI, a second VE surgery might be a possibility for those patients who failed the first operation.

Interestingly, $\mathrm{VE}$ is an effective treatment for azoospermia patients with epididymal obstruction and previous failure to achieve pregnancy by sperm retrieval with ICSI [21]. Three patients diagnosed with OA chose to use the sperm from testicular puncture for ICSI in another hospital but failed possibly due to miscarriage, maturation arrest in utero, or the failure of embryo transfer [21]. After undertaking SA-LIVE in our hospital, all the patients achieved patency: one had natural pregnancy, one underwent IVF after the surgery, and one is still trying to get a natural pregnancy. Furthermore, MEV has significant advantages, such as cost-efficiency, spontaneous pregnancy possibilities, and decreasing the potential risks of congenital disability as compared to ICSI. Thus, microsurgical reconstruction is an effective treatment and should be the first choice for epididymal obstruction patients whose female partners have normal fertility features. Thus, EOA patients with prior failure of ICSI could consider taking LIVE to get pregnant.

This study revealed that if sperm did not show up in the ejaculate after one-year post-operation, ART might be the remedy for such patients. Thus, intra- or postoperative sperm cryopreservation would be helpful. Intraoperative sperm cryopreservation could avoid the additional surgeries for sperm retrieval in case of failure of microsurgery. Postoperative sperm cryopreservation allows sperm from the ejaculate to be used for ART in the event of late failure. In the current cohort, we found out that one patient who achieved recanalization of the vas experienced a recurrence of obstruction after 6 months at the rate of $0.07 \%$, which was lower than that reported previously $(1-50 \%)$ [12, 22]. Sperm cryopreservation was used for a total of 132 patients. Of these, 29 patients who were not successful by vas-mediated patency achieved pregnancy through ICSI by the sperm cryopreserved intraoperatively, and nine successful patients chose to use the sperm from ejaculate to have babies through ART. The pregnancy rate was improved from 30.3 to $43.9 \%$. With the development of the ART technique in the recent decades, the influence of whether the sperm on the next generation was unclear irrespective of its origin from testis or post-epididymis. Thus, taken together, we advocate intra- or postoperative sperm cryopreservation for all OA patients.

\section{Conclusion}

Modified SA-LIVE is preferred when double-armed sutures are not accessible. The expected patency time is within one-year, and ART may be the remedial choice for patients. Assisted with intra-operative sperm cryopreservation, the pregnancy outcomes were improved in patients. The low natural pregnancy rate for the proximal anastomosis suggested that when the obstruction occurs proximally, sperm banking is preferred for future ICSI.

\section{Abbreviations \\ SA-LIVE: Modified single-armed 2-suture longitudinal intussusception vasoepi- didymostomy; VE: Microsurgical vasoepididymostomy; ART: Assisted reproductive techniques; FSH: Follicle-stimulating hormone; T: Testosterone; W: Vasovasostomy; ICSI: Intracytoplasmic sperm injection; OA: Obstructive azoospermia; EOA: Epididymal obstructive azoospermia; IVF: In-vitro fertilization}

\section{Acknowledgements}

Not applicable.

\section{Authors' contributions}

$\mathrm{PL}, \mathrm{EZ}, \mathrm{CCY}, \mathrm{CY}, \mathrm{LZ}, \mathrm{RT}, \mathrm{HC}$, and $\mathrm{YH}$ performed the surgery, $Y Y$ and $\mathrm{NL}$ collected the data. NL and PL analyzed the data and wrote the manuscript. ZL conceived the project, designed the analysis, and supervised the entire study. All of the authors read and approved the final manuscript.

\section{Funding}

This work was supported by grants from National Natural Science Foundation of China (81701524), and Strategic Priority Research Program of the Chinese Academy of Sciences (XDA16020701), and Medical-Engineering (Science) cross-Research Fund of Shanghai Jiao Tong University (YG2017ZD04), and National Natural Science Foundation of China (81871215). The funding body had no control over the study design, or the collection and analysis of the data.

\section{Availability of data and materials}

The datasets used and analyzed during the current study are available from the corresponding author on reasonable request.

\section{Ethics approval and consent to participate}

All procedures performed in studies involving human participants were in accordance with the ethical standards of Institutional Ethical Review Committee of Shanghai general hospital, Shanghai Jiaotong University School of Medicine and with the 1964 Helsinki declaration and its later amendments or comparable ethical standards. The written informed consent was obtained from all individual participants included in the study.

Consent for publication

Not applicable.

Competing interests

The authors declare that they have no competing interests. 


\section{Author details}

'Department of Andrology, the Center for Men's Health, Urologic Medical Center, Shanghai Key Laboratory of Reproductive Medicine, Shanghai General Hospital, Shanghai Jiao Tong University, Shanghai 200080, China.

${ }^{2}$ Anhui Medical University, Hefei 230032, China.

Received: 31 July 2019 Accepted: 4 August 2020

Published online: 12 August 2020

\section{References}

1. De Kretser DM, Baker HW. Infertility in men: recent advances and continuing controversies. J Clin Endocrinol Metab. 1999;84(10):3443-50.

2. Jarow JP, Espeland MA, Lipshultz LI. Evaluation of the azoospermic patient. Urol. 1989;142(1):62-5.

3. Jungwirth A, Diemer T, Kopa Z, Krausz C, Tournaye H, Kelly B, Pal R. EAU guidelines on male infertility 2017; 2017

4. Kolettis PN, Thomas AJ Jr. Vasoepididymostomy for vasectomy reversal: a critical assessment in the era of intracytoplasmic sperm injection. J Urol. 1997;158(2):467-70.

5. Monoski MA, Schiff J, Li PS, Chan PT, Goldstein M. Innovative single-armed suture technique for microsurgical vasoepididymostomy. Urology. 2007; 69(4):800-4.

6. Zhao L, Deng $C H$, Sun $X Z$, Chen Y, Wang WW, Zhao LY, Zeng LY, Tu XA. A modified single-armed technique for microsurgical vasoepididymostomy. Asian J Androl. 2013;15(1):79-82.

7. Hong K, Zhao LM, Xu SX, Tang WH, Mao JM, Liu DF, Jiang H, Ma LL, Qiao J. Multiple factors affecting surgical outcomes and patency rates in use of single-armed two-suture microsurgical vasoepididymostomy: a single surgeon's experience with 81 patients. Asian J Androl. 2016;18(1):129-33.

8. Chan PT, Brandell RA, Goldstein M. Prospective analysis of outcomes after microsurgical intussusception vasoepididymostomy. BJU Int. 2005, 96(4):598-601

9. Dabaja AA, Schlegel PN. Microdissection testicular sperm extraction: an update. Asian J Androl. 2013;15(1):35.

10. Wein AJ, Kavoussi LR, Novick AC, Partin AW, Peters CA, Ramchandani P. Campbell-Walsh urology tenth edition. Philadelphia: Elsevier; 2011.

11. Cornud F, Belin X, Delafontaine D, Amar T, Hélénon O, Moreau J. Imaging of obstructive azoospermia. Eur Radiol. 1997;7(7):1079-85.

12. Farber NJ, Flannigan R, Li P, Li PS, Goldstein M. The kinetics of sperm return and late failure following Vasovasostomy or Vasoepididymostomy: a systematic review. J Urol. 2019;201(2):241-50.

13. Chen XF, Chen B, Liu W, Huang YP, Wang HX, Huang YR, Ping P. Microsurgical vasoepididymostomy for patients with infectious obstructive azoospermia: cause, outcome, and associated factors. Asian J Androl. 2016; 18(5):759-62.

14. Liang ZY, Zhang FB, Li L, Li JP, Wu JG, Chen C, Zhu YM. Clinical application of cross microsurgical vasovasostomy in scrotum for atypical obstructive azoospermia. J Zhejiang Univ Sci B. 2019:20(3):282-6.

15. Zhang GX, Bai WJ, Xu KX, Wang XF, Zhu JC. Clinical observation of loupeassisted intussusception vasoepididymostomy in the treatment of obstructive azoospermia (analysis of 49 case reports). Asian J Androl. 2009; 11(2):193-9.

16. Chan PT. The evolution and refinement of vasoepididymostomy techniques. Asian J Androl. 2013;15(1):49-55.

17. Binsaleh S. Two-suture single-armed longitudinal intussusception vasoepididymostomy for obstructive azoospermia: report of patients characteristics and outcome. Int Urol Nephrol. 2014;46(12):2271-7.

18. Zhao L, Tu XA, Zhuang JT, Chen Y, Wang WW, Zeng LY, Deng CH. Retrospective analysis of early outcomes after a single-armed suture technique for microsurgical intussusception vasoepididymostomy. Andrology. 2015:3(6):1150-3.

19. Lyu KL, Zhuang JT, Li PS, Gao Y, Zhao L, Zhang YD, Zhou MK, Yu JW, Feng $X$, Sun $X Z$, et al. A novel experience of deferential vesselsparing microsurgical vasoepididymostomy. Asian J Androl. 2018;20(6): $576-80$.

20. Hayden RP, Li PS, Goldstein M. Microsurgical vasectomy reversal: contemporary techniques, intraoperative decision making, and surgical training for the next generation. Fertil Steril. 2019;111(3): 444-53.

21. Peng J, Yuan Y, Zhang Z, Cui W, Song W, Gao B. Microsurgical vasoepididymostomy is an effective treatment for azoospermic patients with epididymal obstruction and prior failure to achieve pregnancy by sperm retrieval with intracytoplasmic sperm injection. Hum Reprod. 2014; 29(1):1-7.

22. Alom M, Ziegelmann M, Savage J, Miest T, Kohler TS, Trost L. Office-based andrology and male infertility procedures-a cost-effective alternative. Transl Androl Urol. 2017;6(4):761-72.

\section{Publisher's Note}

Springer Nature remains neutral with regard to jurisdictional claims in published maps and institutional affiliations.
Ready to submit your research? Choose BMC and benefit from:

- fast, convenient online submission

- thorough peer review by experienced researchers in your field

- rapid publication on acceptance

- support for research data, including large and complex data types

- gold Open Access which fosters wider collaboration and increased citations

- maximum visibility for your research: over $100 \mathrm{M}$ website views per year

At BMC, research is always in progress.

Learn more biomedcentral.com/submissions 